\title{
Penerapan Teknologi Augmented Reality untuk Pengenalan Komponen Jaringan dan Cara Kerja TCP/IP berbasis Android
}

\author{
Lena Magdalena ${ }^{1}$, Kusnadi ${ }^{2}$, Muhammad Kahfi ${ }^{3}$ \\ Sekolah Tinggi Manajemen Informatika dan Komputer CIC Cirebon \\ Jl. Kesambi 202, Kota Cirebon, Jawa Barat \\ E-mail : lena.magdalena@cic.ac.id, kusnadi@cic.ac.id, muhammadkahfi18@live.com
}

\begin{abstract}
Absract
Augmented reality is a term for combining real-world environment with virtual worlds. Augmented reality is becoming very popular today because besides interesting, also can be displayed in realtime. In general, augmented reality adds a digital object in reality with reference to specific objects in the real world, for example by using a marker. Therefore, in this thesis aims to create an application that displays a $3 D$ object that contains information about the network components and the workings of TCP / IP by making use of the concept of augmented reality marker technique. Marker is a reference object in the real world as a marker so that the information can be displayed. Marker is made to function to call the $3 D$ objects appear on the screen smartphone that uses the technique of introduction of basic colors of red, green and blue.

The method used consists of several stages of research, namely data collection, analysis and system design and system implementation. Data collection method used is literature. Methods of analysis and design of systems using the Unified Modeling Language (UML). The programming language used for software development are $C$ \# (C-Sharp) with Unity applications and software SketcUp to create 3D objects as well as Android SDK to convert the file into the form of android.

This application is successfully created by displaying a $3 D$ object that can make users excited to get to know the physical network components and requires only an internet connection to download the initial marker.
\end{abstract}

Keyword: Augmented Reality, Marker, Network, 3D Object.

\section{Pendahuluan}

Perkembangan teknologi saat ini mengalami kemajuan yang sangat pesat, dimana teknologi informasi sangat berperan penting dalam kehidupan masyarakat. Mobile phone merupakan salah satu alat komunikasi dan penyedia informasi. Banyak hal yang dapat dilakukan dengan mobile phone, seperti, mengakses internet, mobile banking, mengolah data, mencatat agenda sehari-hari,bermain game. Perkembangan mobile phone sekarang ini lebih cenderung ke arah smartphone hal ini dikarenakan smartphone memiliki fasilitas yang dilengkapi dengan perangkat keras modern sehingga mendukung untuk bekerja lebih optimal. Oleh karena itu pada smartphone banyak digunakan teknologi-teknologi terbaru yang salah satunya adalah Augmented Reality.

Pada tahun 1997 Ronald Azuma menyatakan bahwa Augmented Reality (AR) merupakan sebuah teknologi penggabungan dunia nyata dengan dunia virtual yang bersifat interaktif secara real time. Konsep dasar dari AR itu sendiri yaitu menemukan sebuah marker (penanda) untuk memunculkan objek 2D atau 3D. Pemanfaatan teknologi Augmented Reality banyak digunakan pada bidang edukasi, kedokteran, militer, iklan dan hiburan. Umumnya aplikasi yang menerapkan teknologi Augmented Reality bertujuan untuk memberikan informasi kepada pengguna dengan jelas, menarik, real time, dan interaktif. Seperti contohnya pengenalan komponen jaringan dan cara kerja protokol TCP/IP yang digunakan untuk pembelajaran. Jaringan Komputer merupakan sebuah sistem yang terdiri atas komputer-komputer yang didesain untuk dapat berbagi sumber daya, berkomunikasi dan dapat mengakses informasi.

Belajar mengenal komponen jaringan dan cara kerja TCP/IP umumnya masih menggunakan modul yang berbentuk teks dan gambar yang dapat berdampak kurangnya antusias dalam belajar serta pencarian informasi atau artikel dengan melakukan browsing yang diharuskan membutuhkan koneksi internet, hal ini yang membuat penulis ingin membuat aplikasi tersebut agar pengguna lebih antusias dan memahami komponen jaringan dan cara kerja protokol TCP/IP serta tidak membutuhkan koneksi internet. Dengan memanfaatkan teknologi Augmented Reality, pengenalan komponen jaringan dan cara kerja TCP/IP dapat digantikan dengan objek 3D yang ditampilkan secara virtual dan real time menggunakan perangkat smartphone Android.

Maka dari itu dengan adanya aplikasi ini diharapkan dapat mempermudah pengguna dalam mengenal komponen jaringan dan memahami cara kerja TCP/IP dengan jelas, interaktif tanpa membutuhkan koneksi internet sebagai media pembelajaran.

Berdasarkan penjelasan tersebut penulis berkeinginan untuk membuat sebuah aplikasi yang dapat mempermudah dalam mengenal dan memahami komponen jaringan dan cara kerja TCP/IP dengan menggunakan 
Smartphone dengan platform Android yang berjudul "Penerapan Teknologi Augmented Reality untuk Pengenalan Komponen Jaringan dan Cara Kerja TCP/IP Berbasis Android".

\section{Kajian Pustaka}

\subsection{Aplikasi}

Aplikasi berasal dari kata application yang berisi seperangkat instruksi khusus dalam komputer yang dirancang agar kita menyelesaikan tugas-tugas tertentu yang berjalan pada sistem operasi dan di buat untuk membantu pengguna mengerjakan sesuatu untuk meningkatkan kreativitas.[1]

\subsection{Augmented Reality}

Menurut Ronald T. Azuma (1997), augmented reality (AR) adalah penggabungan benda-benda nyata dan maya di lingkungan nyata, berjalan secara interaktif dalam real-time, dan terdapat integrasi antar benda dalam tiga dimensi. Secara umum untuk membangun augmented reality dibutuhkan minimal komponen-komponen seperti, input device, output device, tracker, dan computer. Augmented Reality diterapkan dibeberapa bidang seperti, bidang militer, bidang kesehatan, dan bidang periklanan. [2]

Secara umum untuk membangun augmented reality dibutuhkan minimal komponen-komponen:

1. Input Device

Input device atau alat input berfungsi sebagai sensor untuk menerima input dalam dunia nyata. Input device yang biasa digunakan dalam AR adalah kamera, kamera pada handphone atau webcam saat ini banyak digunakan sebagai input device bagi aplikasi AR.

2. Output Device

Output device atau alat output berfungsi sebagai display hasil AR. Output device yang biasa digunakan adalah monitor dan head mounted display. Head mounted display adalah alat yang digunakan di kepala, mirip kacamata, untuk menampilkan hasil AR. Head mounted display biasanya sudah terintegrasi dengan kamera di bagian atasnya, sehingga selain sebagai alat output juga sebagai alat input.

\section{Tracker}

Tracker adalah alat pelacak agar benda maya tambahan yang dihasilkan berjalan secara real-time atau mungkin interaktif walaupun benda nyata yang jadi induknya digeser-geser, benda maya tambahannya tetap mengikuti benda nyata yang jadi induknya. Biasanya tracker ini berupa marker atau penanda semacam striker mirip QR Code yang bisa ditempel/dipasang di benda nyata.

4. Komputer

Komputer berfungsi sebagai alat pemroses agar program AR bisa berjalan. Komputer disini bisa berupa PC atau embedded system yang dipasang pada alat (contohnya dipasang di mounted head display).

Menurut Khusnul Khotimah pada skripsinya yang berjudul "Aplikasi Tutorial Rukun Umroh Menggunakan Augmented Reality Berbasis Android" menyebutkan bahwa marker merupakan suatu pola yang dapat dibuat dalam bentuk gambar dan dapat dikenali oleh perangkat optik atau kamera. Metode pada Augmented Reality dapat dibagi dua yaitu :

1. Markerless, merupakan suatu metode yang tidak membutuhkan sebuah marker untuk menampilkan objekobjek virtual. Pada saat ini terdapat beberapa macam metode markerless seperti :

a. Face Tracking menggunakan algoritma yang dapat mengenali wajah manusia secara umum dengan mengenali posisi mata, hidung, dan mulut.

b. 3D Object Tracking dapat mengenali semua bentuk benda disekitar seperti, mobil, meja, televisi dan sebagainya.

c. Motion Tracking merupakan teknik pada komputer yang dapat menangkap gerakan.

d. GPS Based Tracking, merupakan metode yang memanfaatkan GPS dan kompas pada smartphone, aplikasi akan mengambil data dari GPS dan kompas kemudian menampilkannya dalam bentuk arah yang diinginkan secara real time.

2. Marker Based Tracking, biasanya merupakan ilustrasi hitam putih persegi dengan batas hitam tebal dan latar belakang putih. Komputer akan mengenali posisi dan orientasi marker dan menciptakan dunia virtual 3D yaitu titik $(0,0,0)$ dan tiga sumbu yaitu X, Y, Z. Marker based tracking ini sudah lama dikembangkan sejak tahun 80-an dan pada awal 90-an mulai dikembangkan untuk penggunaan Augmented Reality.[6]

\subsection{Jaringan Komputer}

Jaringan komputer adalah sebuah kumpulan komputer, printer dan peralatan lainnya yang terhubung dalam satu kesatuan. Informasi dan data bergerak melalui kabel-kabel atau tanpa kabel sehingga memungkinkan pengguna jaringan komputer dapat saling bertukar dokumen dan data, mencetak pada printer yang samadan bersama-sama menggunakan hardware/software yang terhubung dengan jaringan. Setiap komputer, printer atau periferal yang terhubung dengan jaringan disebut node. Sebuah jaringan komputer dapat memiliki dua, puluhan, ribuan atau bahkan jutaan node. [3]

\subsection{Komponen Jaringan}


Beberapa komponen jaringan komputer, dimana komponen jaringan yang dibutuhkan dapat disesuaikan dengan kebutuhan, seperti: ethernet card, hub, switch, router, repeater, bridge, modem, kabel, konektor, crimping tool, dan cable tester. [3]

\subsection{Protokol TCP/IP}

Protokol adalah sekumpulan aturan dalam komunikasi data. Protokol mengatur bagaimana terjadinya hubungan dan perpindahan data antara dua atau lebih komputer. Pada masa ARPANET protokol yang digunakan untuk komunikasi data adalah NCP (Network Communication Protocol), semakin lama ukuran ARPANET semakin membesar dan NCP tidak sanggup menampung node yang lebih besar. DARPA kemudian mendanai pembuatan protokol komunikasi lebih umum yang dinamai protokol TCP/IP. Departemen Pertahana Amerika menyatakan TCP/IP menjadi standar untuk jaringannya pada tahun 1982. [4]

\subsection{Android}

Android adalah sebuah sistem operasi untuk perangkat mobile berbasis linux yang mencakup sistem operasi, middleware dan aplikasi. Aplikasi Android ditulis dalam bahasa pemrograman java. Kode java dikompilasi bersama data file resource yang dibutuhkan oleh aplikasi, di mana prosesnya dipackage oleh tools yang dinamakan "apt tools" ke dalam paket Android sehingga menghasilkan file dengan ekstensi apk, dan nantinya dapat di install di perangkat mobile. [5]

\subsection{Analisis dan Perancangan Sistem}

Analisa sistem merupakan tahap mengidentifikasi kebutuhan apa yang harus dipenuhi dalam pembuatan perangkat lunak tersebut. Adapun dalam pembuatan laporan ini penyusun membagi analisa sistem kedalam beberapa tahap, yaitu: analisa masalah, kebutuhan perangkat keras, kebutuhan perangkat lunak, dan analisa proses implementasi. Menganalisis sistem sangat diperlukan karena analisa tersebut akan dijadikan dasar untuk perancangan sistem. [1]

\section{Analisa dan Perancangan}

\subsection{Use Case Diagram}

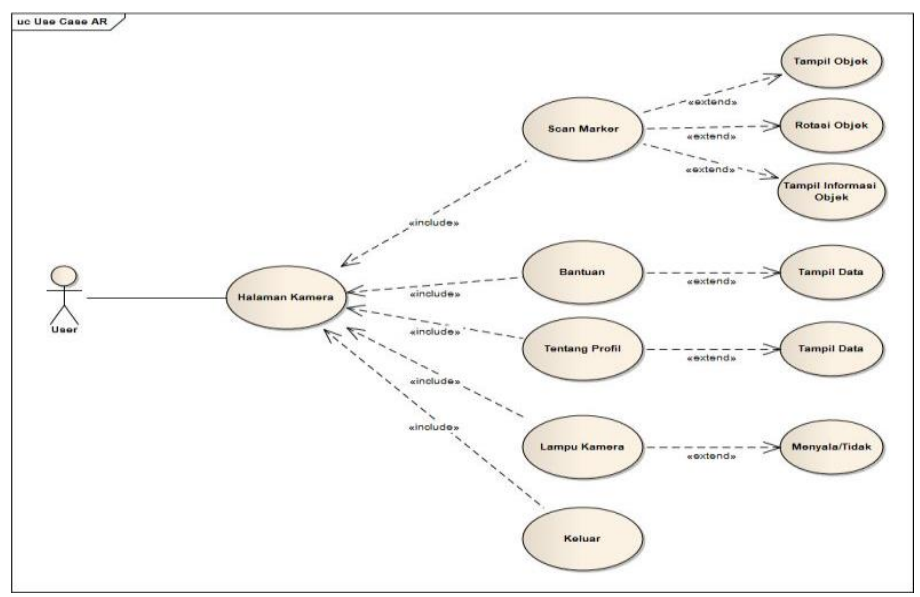

Gambar 1 Use Case Diagram 


\subsection{Activity Diagram}

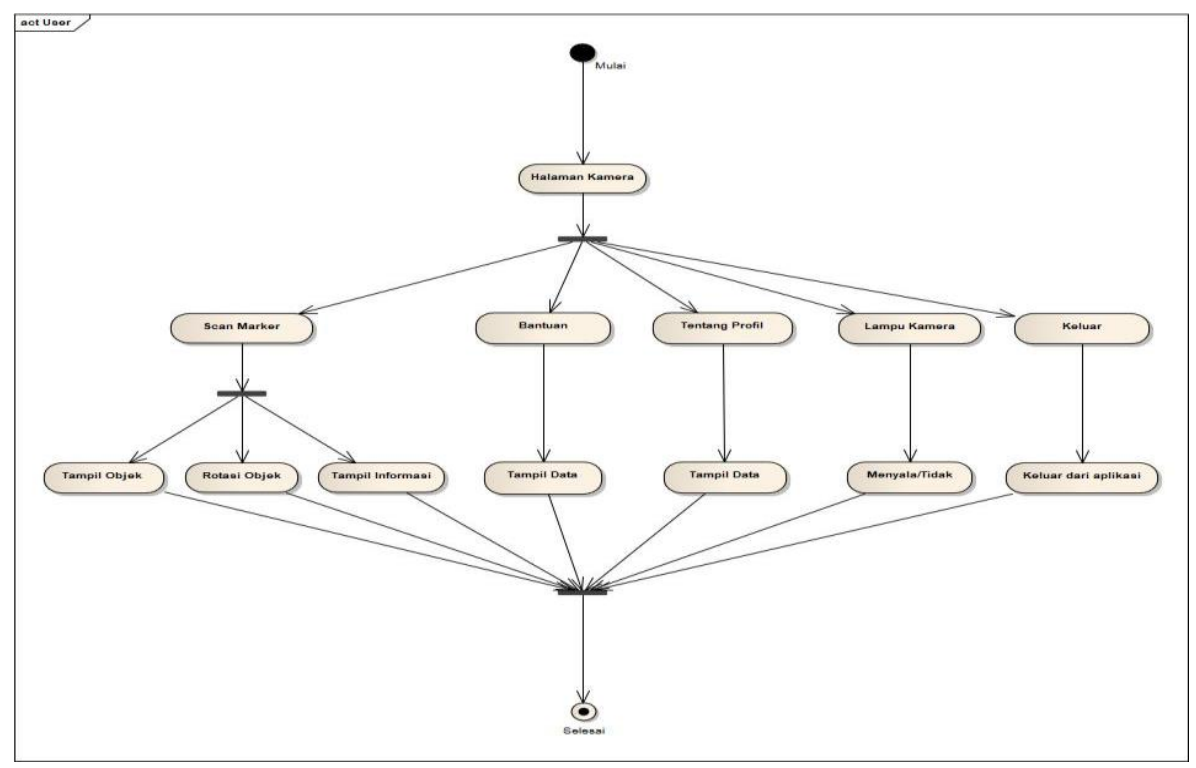

Gambar 2 Activity Diagram

3.3. Sequence Diagram

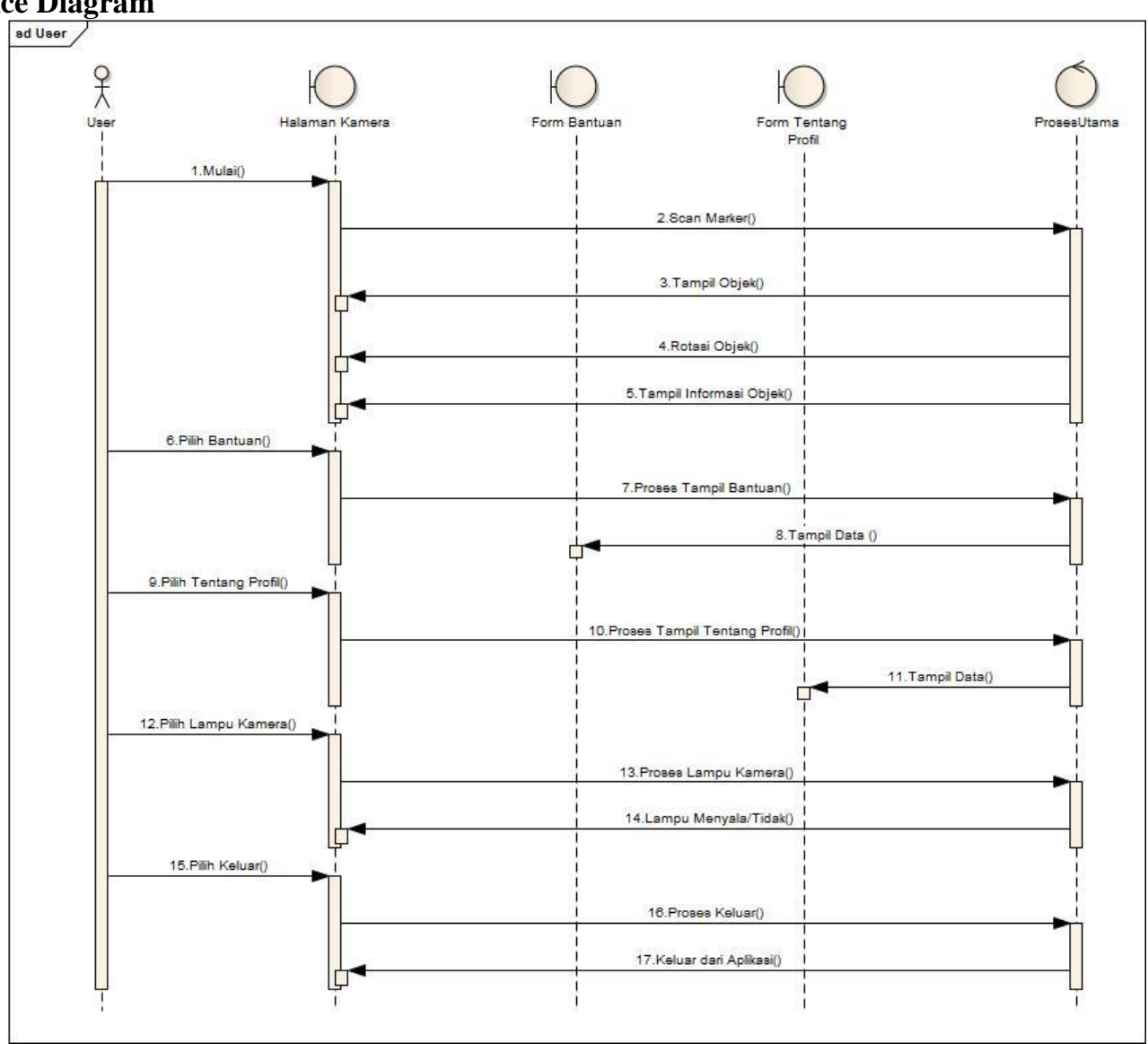

Gambar 3 Sequence Diagram 


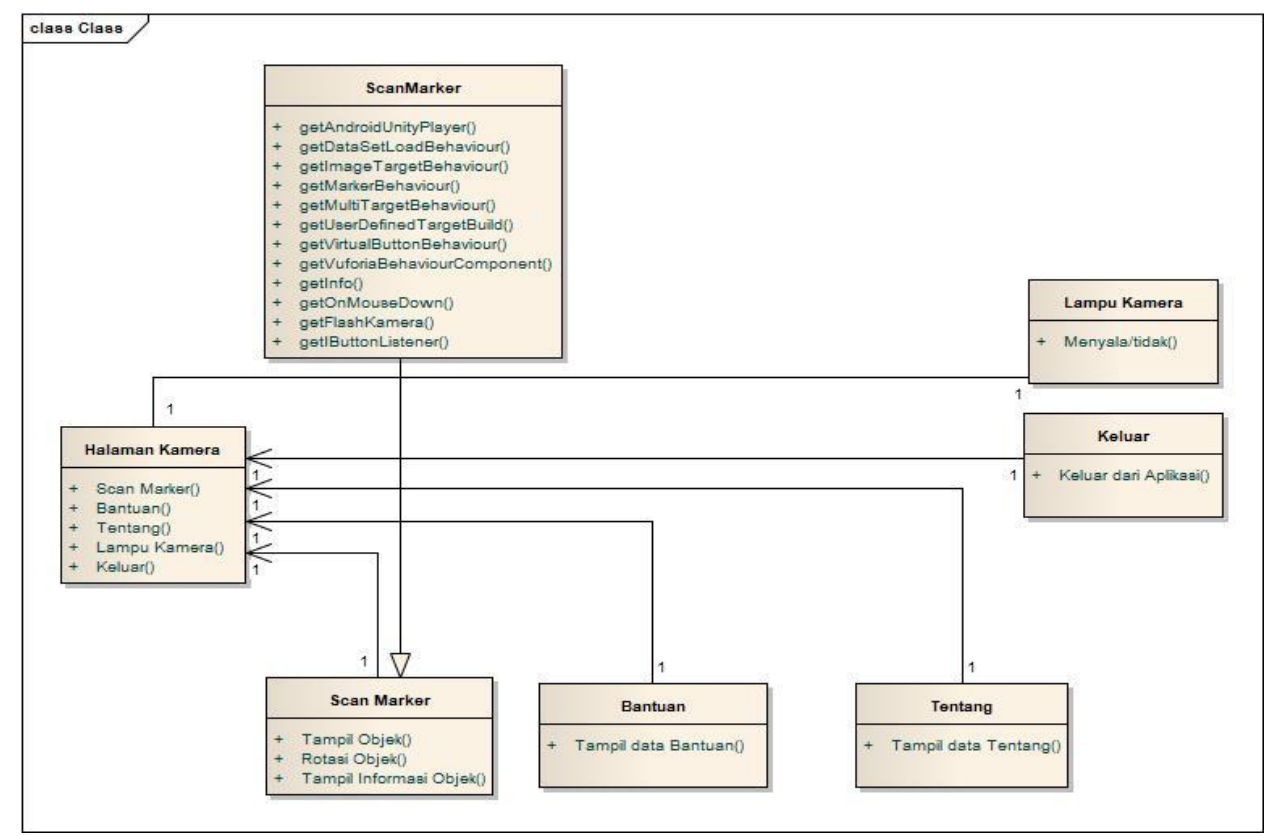

Gambar 4 Class Diagram

\section{Hasil dan Pembahasan}

4.1. Tampilan Halaman Splash Screen

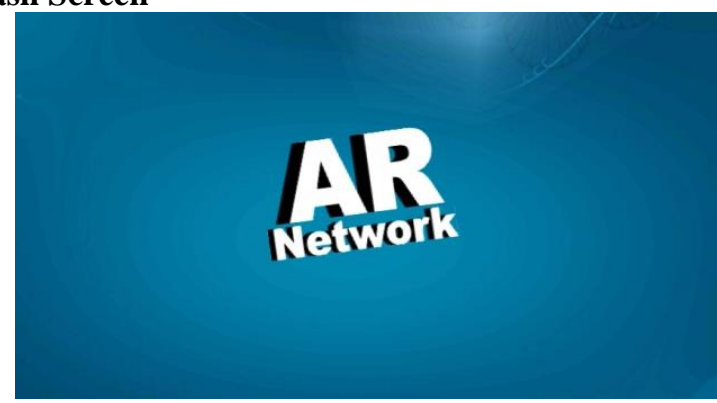

Gambar 5 Tampilan Splash Screen

Keterangan :

Pada gambar 4.1. ini merupakan halaman awal aplikasi di buka yaitu halaman Splash Screen yang akan menuju ke halaman kamera.

\subsection{Tampilan Halaman Kamera (Menu Utama)}

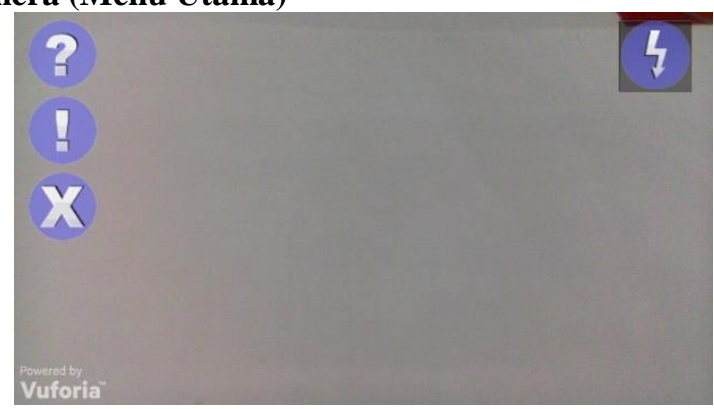

Keterangan :

Gambar 6 Tampilan Halaman Kamera (Menu Utama)

Pada gambar 4.2. adalah tampilan halaman kamera yang berfungsi untuk mencari marker,menampilkan form bantuan,tentang dan mengaktifkan lampu kamera. 


\subsection{Tampilan Form Bantuan}

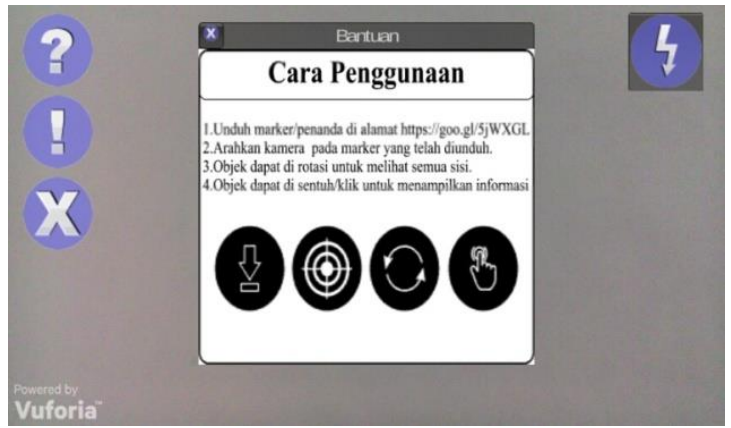

Gambar 7 Tampilan Form Bantuan

Keterangan :

Gambar 4.3. menampilkan halaman bantuan yang berisi tata cara menggunakan aplikasi ini yang di tampilkan secara bertahap.

\subsection{Tampilan Halaman Scan Marker untuk Bridge}

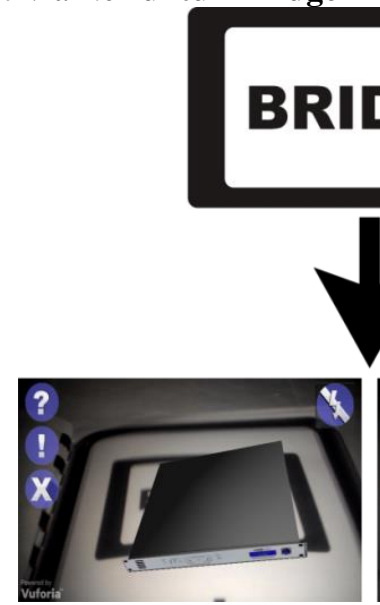

(a)

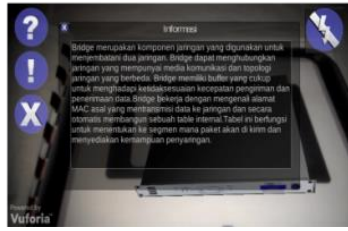

(b)

Gambar 8 Tampilan Halaman Scan Marker untuk Bridge

Keterangan :

Gambar 4.5. ini menampilkan hasil dari proses scan marker bridge. Hanya menampilkan objek 3 dimensi dan melakukan rotasi (a). Menampilkan informasi dari objek tersebut ketika di sentuh objeknya (b).

\subsection{Tampilan Halaman Scan Marker untuk Crimping Tool}

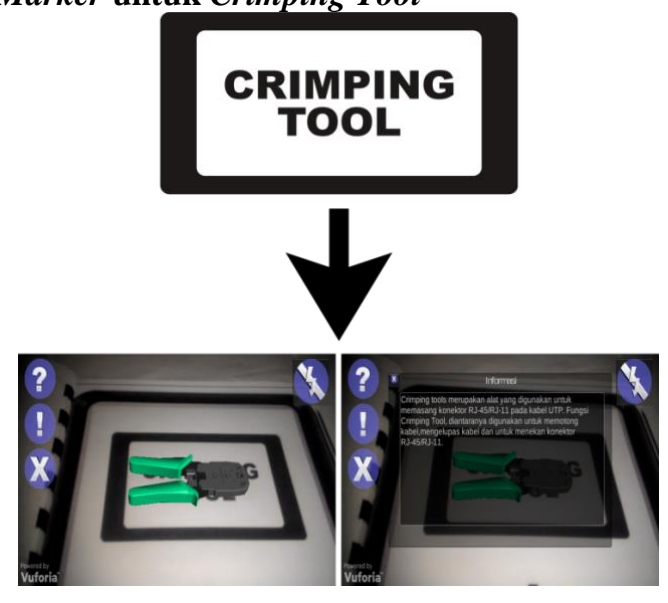

(a)

(b)

Gambar 9 Tampilan Halaman Scan Marker untuk Crimping Tool 


\section{Keterangan :}

Gambar 4.6. ini menampilkan hasil dari proses scan marker crimping tool. Hanya menampilkan objek 3 dimensi dan melakukan rotasi (a). Menampilkan informasi dari objek tersebut ketika di sentuh objeknya (b).

\subsection{Tampilan Halaman Scan Marker untuk Hub}

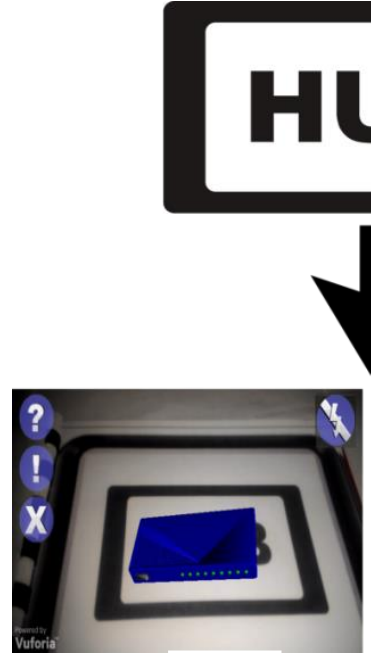

(a)

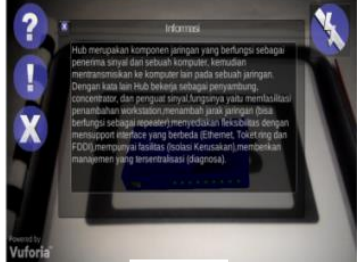

(b)

Keterangan :

\section{Gambar 10 Tampilan Halaman Scan Marker untuk Hub}

Gambar 4.7. ini menampilkan hasil dari proses scan marker hub. Hanya menampilkan objek 3 dimensi dan melakukan rotasi (a). Menampilkan informasi dari objek tersebut ketika di sentuh objeknya (b).

\subsection{Tampilan Halaman Scan Marker Kabel}

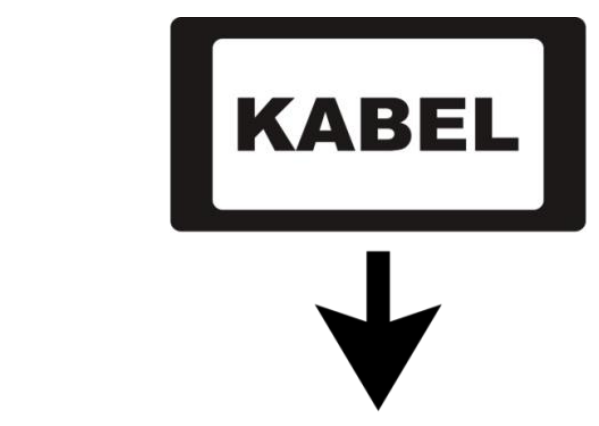

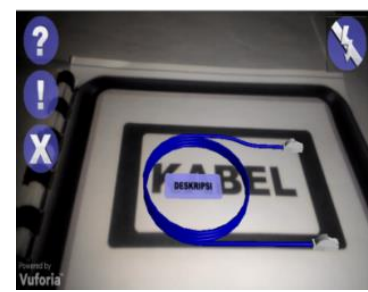

(a)

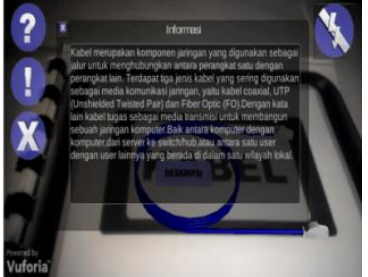

(b)

\section{Gambar 11 Tampilan Halaman Scan Marker Kabel}

Keterangan :

Gambar 4.8. ini menampilkan hasil dari proses scan marker kabel. Hanya menampilkan objek 3 dimensi dan melakukan rotasi (a). Menampilkan informasi dari objek tersebut ketika di sentuh objeknya (b).

\subsection{Tampilan Halaman Scan Marker Konektor}




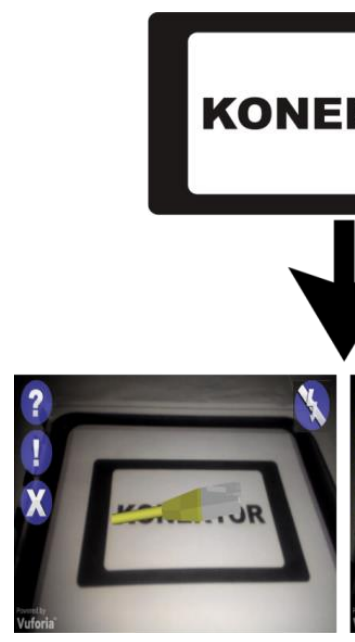

(a)

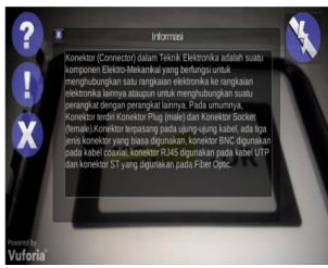

(b)

Keterangan :

Gambar 12 Tampilan Halaman Scan Marker Konektor

Gambar 4.9. ini menampilkan hasil dari proses scan marker Konektor. Hanya menampilkan objek 3 dimensi dan melakukan rotasi (a). Menampilkan informasi dari objek tersebut ketika di sentuh objeknya (b).

\subsection{Tampilan Halaman Scan Marker Ethernet Card}

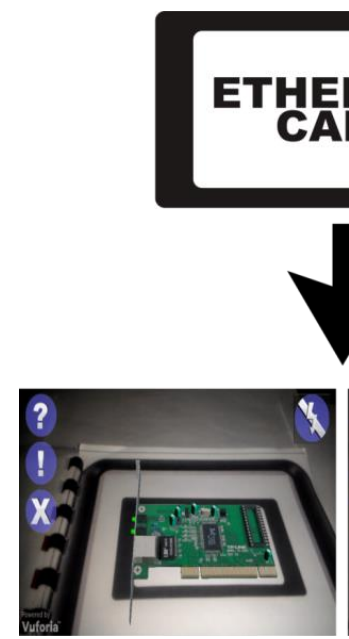

(a)

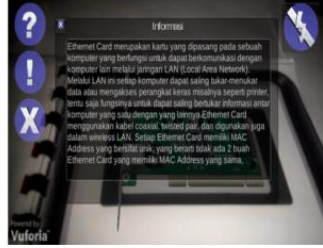

(b)

Keterangan :

Gambar 13 Tampilan Halaman Scan Marker Ethernet Card

Gambar 4.10. ini menampilkan hasil dari proses scan marker Ethernet Card. Hanya menampilkan objek 3 dimensi dan melakukan rotasi (a). Menampilkan informasi dari objek tersebut ketika di sentuh objeknya (b).

\subsection{Tampilan Halaman Scan Marker Modem}




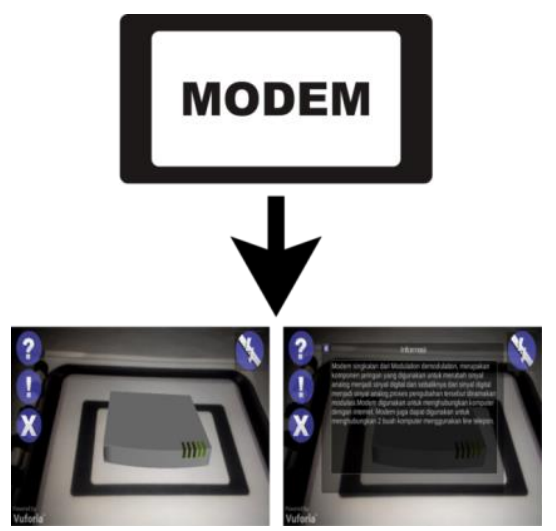

(a)

(b)

Keterangan :

Gambar 15 Tampilan Halaman Scan Marker Modem

Gambar 4.11. ini menampilkan hasil dari proses scan marker Modem. Hanya menampilkan objek 3 dimensi dan melakukan rotasi (a). Menampilkan informasi dari objek tersebut ketika di sentuh objeknya (b).

\subsection{Tampilan Halaman Scan Marker Repeater}

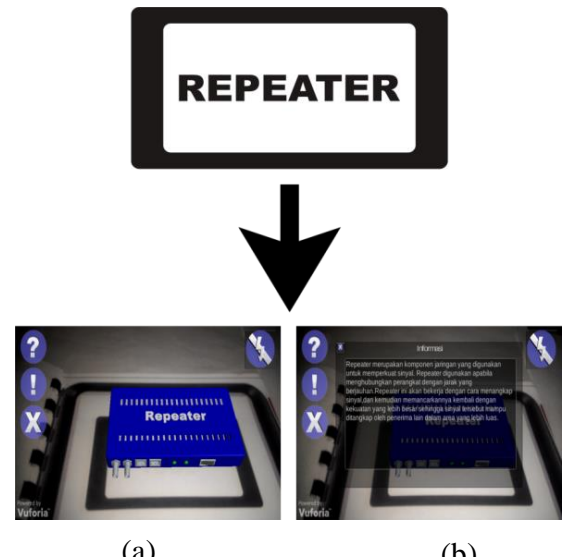

(a)

(b)

Keterangan :

Gambar 16 Tampilan Halaman Scan Marker Repeater

Gambar 4.12. ini menampilkan hasil dari proses scan marker Repeater. Hanya menampilkan objek 3 dimensi dan melakukan rotasi (a). Menampilkan informasi dari objek tersebut ketika di sentuh objeknya (b).

\subsection{Tampilan Halaman Scan Marker Router}

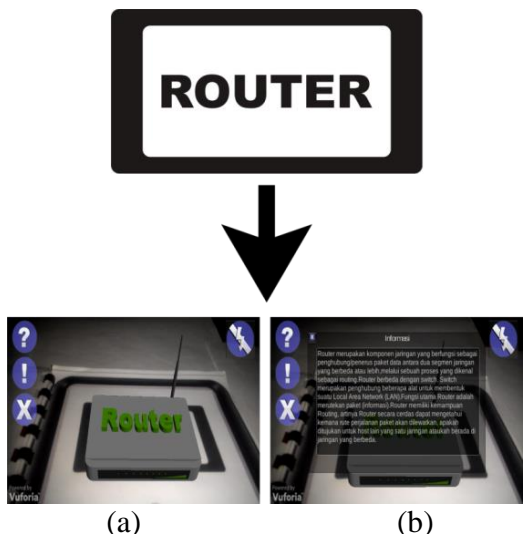

Gambar 17 Tampilan Halaman Scan Marker Router

Keterangan : 
Gambar 4.13. ini menampilkan hasil dari proses scan marker Router. Hanya menampilkan objek 3 dimensi dan melakukan rotasi (a). Menampilkan informasi dari objek tersebut ketika di sentuh objeknya (b).

\subsection{Tampilan Halaman Scan Marker Switch}

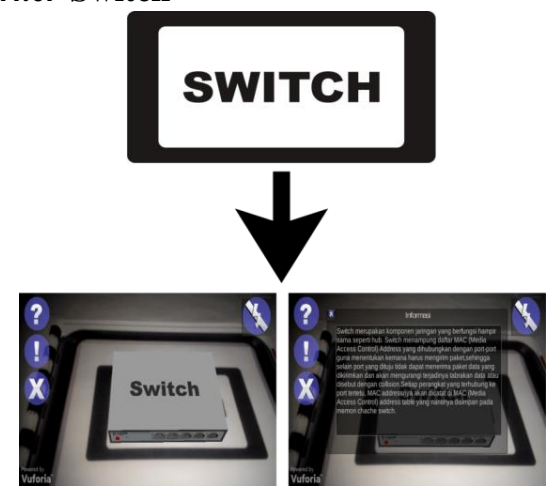

(a)

(b)

Keterangan :

Gambar 18 Tampilan Halaman Scan Marker Switch

Gambar 4.14. ini menampilkan hasil dari proses scan marker Switch. Hanya menampilkan objek 3 dimensi dan melakukan rotasi (a). Menampilkan informasi dari objek tersebut ketika di sentuh objeknya (b).

\subsection{Tampilan Halaman Scan Marker Cable Tester}

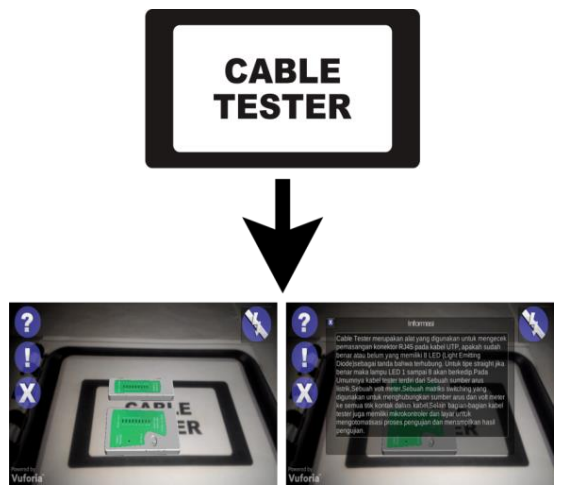

(a)

(b)

Keterangan :

Gambar 19 Tampilan Halaman Scan Marker Cable Tester

Gambar 4.15. ini menampilkan hasil dari proses scan marker Cable Tester. Hanya menampilkan objek 3 dimensi dan melakukan rotasi (a). Menampilkan informasi dari objek tersebut ketika di sentuh objeknya (b).

\subsection{Tampilan Halaman Scan Marker TCP}

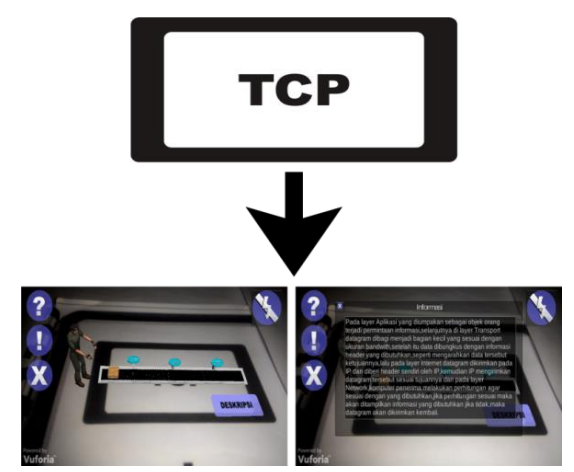

Keterangan :

Gambar 20 Tampilan Halaman Scan Marker TCP 
Gambar 4.16. ini menampilkan hasil dari proses scan marker TCP. Menampilkan animasi objek 3 dimensi dan tidak dapat melakukan rotasi, hanya dapat menampilkan informasi dari objek tersebut ketika di sentuh objeknya.

\section{Kesimpulan Dan Saran}

Setelah skripsi aplikasi berbasis android ini diselesaikan maka penulis dapat menarik kesimpulan sebagai berikut :

1. Aplikasi Augmented Reality berbasis Android berhasil dibuat dengan beberapa fitur seperti, rotasi dan menyalakan lampu cahaya (flash).

2. Aplikasi yang dibuat menyajikan informasi berbentuk objek 3D, sehingga pengguna tidak harus menggunakan modul yang berbentuk teks dan gambar yang dapat membuat kurangnya antusias untuk mengenal komponen jaringan.

3. Aplikasi yang dibuat hanya membutuhkan koneksi diawal untuk mengunduh marker, setelah itu pengguna dapat menggunakan aplikasi ini dimanapun dan kapanpun tanpa membutuhkan koneksi internet.

4. Aplikasi ini mempermudah pengguna mengenal komponen jaringan dan cara kerja TCP/IP.

Aplikasi yang dibuat masih sangatlah sederhana dan masih banyak yang harus dilengkapi dan diperbaiki, beberapa hal yang dapat dikembangkan dalam aplikasi ini adalah sebagai berikut :

1. Memperbaiki tampilan interface dan objek 3D yang dirasa masih kurang baik.

2. Menambahkan fitur-fitur lain seperti zoom, capture image dan sound.

3. Memperluas cakupan konten, tidak hanya pada komponen jaringan secara fisik.

4. Menggunakan algoritma/metode tertentu untuk mengenal huruf, sehingga marker dapat di create sendiri oleh pengguna.

\section{Daftar Pustaka}

[1] Andi. "Mudah Membuat Game 3 Dimensi menggunakan Unity 3D": ANDI, 2014.

[2] Billinghurst. "Spatial Augmented Reality Merging Real and Virtual Worlds". CRC Press, 2007.

[3] Andi. "Membangun Sistem Jaringan Komputer". MADCOMS, 2009.

[4] Sofana, Iwan. “CISCO CCNA \& Jaringan Komputer”. Gramedia, 2011.

[5] Suprianto, Dodit. Agustina, Rini, M.Pd., S.Kom., "Pemrograman Aplikasi Android". Informatika, 2012.

[6] Khusnul Khotimah. "Aplikasi Tutorial Rukun Umroh Menggunakan Augmented Reality Berbasis Android". Jurnal :1, 2, 3, 4, 5., 2014.

[7] Jurnal Ilmiah Komputer dan Informatika. Sofiansah Tofan. 2012.

[8] SIANIPAR, R.H. "Pemrograman C\#”. Informatika. 2014.

[9] Suprianto, Dodit. "Pemrograman Aplikasi Android”. Informatika. 2012.

[10] Prabowo, Widodo. "Menggunakan UML". Informatika. 2011.

[11] Chandra, Handi. “7 Jam Belajar Interaktif SketchUp 2014 untuk Orang Awam”. Maxicom. 2014.

[12] A.S, Rosa. "Rekayasa Perangkat Lunak Terstruktur dan Berorientasi Objek" Informatika. 2011.

[13] http://gameprogramming.blog.ittelkom.ac.id diakses 29-05-2015

[14] http://forum.unity3d.com/forums/scripting.12/ diakses 25-07-2015

[15] http://forum.unity3d.com/categories/graphics.75/ diakses 23-07-2015

[16] http://docs.unity3d.com/Manual/index.html diakses 23-07-2015

[17] https://developer.vuforia.com/targetmanager/licenseManager/licenseListing diakses 20-07-2015 